\title{
OBEs in the Blind
}

To the Editor:

Harvey J. Irwin (1987) suggested that sensory deprivation may not be the fundamental cause of the out-of-body experience (OBE). The reason he cited is that although sensory bombardment and extreme elation do not entail sensory restriction, they facilitate the OBE. He added that these and other OBE-conducive situations promote "a state of strong absorption in the content of one's experience or mentation" (p. 58) and therefore the process of absorption should be considered central to the occurrence of the OBE.

I would like to point out that I (Krishnan, 1985) have indicated how both sensory bombardment and states of intense positive emotions can lead to a decrease in, and invariance of, sensory (that is, information) input to the brain. The important role that the reticular formation plays in reducing information input in situations of sensory deprivation and sensory overload has been emphasized by Donald B. Lindsley (1961). As far as I can see, the net effect of absorption, which involves withdrawal of attention, deliberately or otherwise, from sensory and proprioceptive stimulation (Irwin, 1980), is a reduction of input of information to the brain.

Secondly, I doubt whether we can say with certainty what is central to the occurrence of the OBE in the present state of our knowledge about the experience. It has been studied in depth only from a psychological perspective; until it is studied as well from other perspectives, such as the neurological or biochemical, I think we should suspend judgment.

I appreciate Irwin's thoughtful comments on my suggestion that study of visual OBEs in congenitally blind persons may help us understand whether or not out-of-body vision has a physical basis. I hope his 
comments will stimulate research in this area. For my part, I have so far not been able to find an instance of an OBE in a person born totally blind.

We could perhaps approach this question in another way. We might investigate whether or not the veridical out-of-body vision of those with visual defects is disturbed. If it is impaired, it is obvious that outof-body vision, when it is veridical, does not operate independently of the visual system, and from the kinds of defects that affect out-of-body sight we might gain an idea of the anatomical structures involved in it.

It is not possible to resolve this issue conclusively on the basis of published cases of out-of-body sight in people with a visual disability (e.g., Davis-Cambridge, 1976; Green, 1968, pp. 32-33; Irwin, 1987, Case 3; Ring, 1981, p. 38, footnote). Those cases have not been corroborated independently, and it therefore can be argued that their visual content was hallucinatory. The experience of Juanita DavisCambridge (1976), who became blind owing to a hemorrhage into the vitreous humor of her eyes, is nevertheless of interest. She had her OBE unexpectedly in the early hours of the morning and, unlike the respondents of Celia Green (1968) and Kenneth Ring (1981), who claimed clear out-of-body vision despite their weak eyesight, DavisCambridge could see herself and her friend lying beside her only as shadowy forms. Was the lack of clarity due to her disability or her room being in darkness? Or was it simply an exceptional case?

Claims of out-of-body vision that have been systematically verified and found veridical (e.g., Sabom, 1982; Clark, 1984) also do not help, as the investigators have not provided any information about the eyesight of the subjects. I would suggest that in future investigations, data on the eyesight of experiencers should be routinely elicited.

I take this opportunity to draw attention to some other aspects of outof-body vision about which there is also little or no information in the literature. If we fill in these gaps, we may perhaps be able to advance our understanding of this phenomenon.

1. According to many OBErs, they saw their physical bodies and/ or surroundings suddenly from a position above the plane of the body. Some experiencers have, however, felt a sensation of falling slowly below the level of the body and then rising above it (Green, 1968, p. 46; Moody, 1977, pp. 33-36). Those experiencers report that, as they were moving up above the body, they could see below them, but it is unclear whether the impression of descending below the plane of the body is accompanied by any visual experience. One subject experienced tac- 
tile bodily sensations as he felt that he was crawling on the floor, but had no visual sensations (Greene, personal communication, 1985). This aspect of the $\mathrm{OBE}$ requires investigation because if, as a rule, subjects have no visual experience while they seem to be below the body, then an elevated perspective is in some way connected with the mechanism underlying out-ofbody vision.

The reason why the vantage point appears to be located above body level has yet to be elucidated, though a number of writers have offered speculations (Blackmore, 1983a, p. 150; Greene, 1983; Irwin, 1985, pp. 130-131; Jung, 1969, p. 509). We may also note that Georg von Bekesy (1967, pp. 127-129) has cited a somewhat similar experience in the auditory modality. He wrote of a person who listened to radio music wearing earphones and always heard the music in back of his head. Over a two-hour session, he showed the man how he could localize the music in front of him or behind him, as he pleased. Bekesy observed that when a person wears wellmatched earphones on both ears "the acoustical situation provides a free choice of localizing the imaged sound source in front, within the head, or behind. The determining condition will probably be some early experience relative to the situation."

2. It appears from some accounts of multiple OBEs that although the localization of the vantage point may be peculiar to each experiencer, it is invariant for him or her over several episodes. For example, one of Green's respondents said that she had between 20 and 30 OBEs in the course of five years, and on each occasion she felt that she had seen herself from behind her right shoulder as she worked at her typewriter (Green, 1968, pp. 26-27). Another respondent felt that the viewpoint was always in the far right-hand corner of the ceiling of her room (p. 57). One of Michael Sabom's interviewees observed that in each of his four OBEs he underwent over a ten-year period, his vantage point was from the upper left (Sabom, 1982, pp. $72 \& 121$ ).

It is difficult to judge from the literature whether an invariance of spatial relationship between physical body and vantage point is a common feature of multiple OBEs, as the subjects have not been asked specifically about it; the observations cited above were made voluntarily. If future research 
reveals that that invariance is a consistent feature, we need to explore what that signifies.

3. A few OBErs have said that they saw the physical body as a mirror image. As Irwin pointed out (1985, pp. 90-93), it is unclear whether the experiencers used the term "mirror image" as a metaphor for "identical replica" or whether they meant that the body looked laterally reversed. His conclusion, based on the scant data available on this feature, was that the subjects most likely perceived the body without right-left reversal. But then, in the experimental situation, the $\mathrm{OBE}$ adepts Stuart Blue Harary (Rogo, 1978, p. 185, footnote) and Ingo Swann (Mitchell, 1987, p. 72) have on occasion exhibited mirror vision with respect to some of the targets they identified. The possibility of lateral reversal cannot therefore be ruled out.

Some questions arise in this connection. Why is it that lateral reversal occurs only at times? What is the reason for mirror vision? Neither Harary nor Swann seem to have seen their physical bodies in mirror image. Does that mean that only elements other than the physical body are seen in that way? Fresh data need to be collected and examined to find answers to these questions. In attempting to account for mirror vision, we may keep in mind the finding from animal experiments that lateral reversal is a characteristic of transfer of visual information from one brain hemisphere to the other (Noble, 1966).

4. There is no indication in OBE accounts of experiencers making mistakes in the perception of the physical body. The deviations from actuality that are sometimes reported pertain to the subjects' physical surroundings or their self-image, or parasomatic form. For example, some OBErs have seen in the physical environment objects that were not actually there. But there does not seem to be an instance of an experiencer having made such errors of commission in viewing the body, such as seeing it in clothing that he or she was not wearing at the time of the OBE. If the physical body observed by the OBEr is of subjective origin, as several writers have suggested (Blackmore, 1983b; Irwin, 1985; Siegel, 1980), is it not likely that departure from reality in some detail or other will sometimes occur? I would suggest investigating the accuracy of out-ofbody vision of the body itself. 
5. The target detection experiments conducted in the past by inducing OBEs in experimental subjects were designed to investigate whether they could identify target objects located away from their immediate vicinity. Those subjects have not been very successful at identifying distant targets (Blackmore, 1983, Chapter 18; Irwin, 1985, pp. 53-73), but did they see their physical surroundings as, for instance, many OBErs interviewed by Sabom did? There is hardly any information in this regard in the experimental reports. I think experimental subjects should be tested for their near perception as well, with target materials kept near them but out of their visual fields. If they score positively on both tests, we can compare their near and distant out-of-body vision in respect to accuracy, clarity of vision, number of details observed, etc. That may provide a basis for considering whether perception of near and remote objects is mediated by the same mechanism.

We may also study comparatively the near and far out-ofbody vision of those who report moving to a distant physical location after witnessing events near their bodies, provided their remote perceptions can be corroborated. Kimberly Clark (1984) verified the distant perception of a cardiac arrest patient and found it to be veridical, but she does not appear to have checked the patient's near out-of-body vision.

6. Out-of-body vision arising during electrical stimulation of certain areas of the brain has not been studied to determine whether subjects see anything outside of their visual field. This omission should be repaired.

\section{References}

Bekesy, G. von. (1967). Sensory inhibition. Princeton, NJ: Princeton University Press. Blackmore, S. J. (1983 a). Are out-of-body experiences evidence for survival? Anabiosis, 3, 137-155.

Blackmore, S. J. (1983 b). Beyond the body: An investigation of out-of-the-body experiences. London, England: Granada Publishing Ltd.

Clark, K. (1984). Clinical interventions with near-death experiencers. In B. Greyson \& C. P. Flynn (Eds.), The near-death experience: problems, prospects, perspectives. Springfield, IL: Charles C. Thomas.

Davis-Cambridge, J. (1976). Parapsychology: A new perspective on dying? Suicide and Life-Threatening Behavior, 6, 179-188. 
Green, C. E. (1968). Out of the body experiences. Oxford, England: Institute of Psychophysical Research.

Greene, F. G. (1983). Multiple mind/body perspectives and the out-of-body experience. Anabiosis, 3, 39-62.

Irwin, H. J. (1980). Out of the body Down Under: Some cognitive characteristics of Australian students reporting OBEs. Journal of the Society for Psychical Research, 50, 448-459.

Irwin, H. J. (1985). Flight of mind: A psychological study of the out-of-body experience. Metuchen, JH: Scarecrow Press.

Irwin, H. J. (1987). Out-of-body experiences in the blind. Journal of Near-Death Studies, 6, 53-60.

Jung, C. G. (1969). The structure and dynamics of the psyche (2nd ed.). London, England: Routledge \& Kegan Paul.

Krishnan, V. (1985). Near-death experiences: Evidence for survival? Anabiosis, 5, 21-38.

Lindsley, D. B. (1961). Common factors in sensory deprivation, sensory distortion, and sensory overload. In P. Solomon, P. E. Kubzansky, P. H. Leiderman, J. H. Mendelson, R. Trumbull, \& D. Wexler (Eds.), Sensory deprivation (pp. 174-194). Cambridge, MA: Harvard University Press.

Mitchell, J. L. (1987). Out-of-body experiences: A handbook. New York, NY: Ballantine Books.

Moody, R. A. Jr. (1977.) Life after life. Bombay, India: India Book House.

Noble, J. (1966). Mirror-images and the forebrain commissures of the monkey. Nature, 211, 1263-1266.

Ring, K. (1981). Paranormal and other non-ordinary aspects of near-death experiences: Implications for a new paradigm. Essence, 5, 33-51.

Rogo, D. S. (1978). Experiments with Blue Harary. In D. S. Rogo (Ed.), Mind beyond the body (pp. 170- 192). Harmondsworth, England: Penguin Books.

Sabom, M. (1982). Recollections of death: A medical investigation. New York, NY: Harper \& Row.

Siegel, R.K. (1980). The psychology of life after death. American Psychologist, 35, 911-931.

\author{
V. Krishnan \\ Post Box 553 \\ Fraser Town \\ Bangalore \\ Karnataka 560005 \\ India
}

